\title{
Controlled Release Compound Based on Metanilate-Layered Double Hydroxide Nanohybrid
}

\begin{abstract}
Metanilate-layered double hydroxide nanohybrid compound was synthesized for controlled release purposes through co-precipitation method of the metal cations and organic anion. The effect of various divalent metal cations (M2+), namely $\mathrm{Zn} 2+, \mathrm{Mg} 2+$ and $\mathrm{Ca} 2+$ on the formation of metanilate-LDH nanohybrids, in which metanilate anion was intercalated into three different layered double hydroxide (LDH) systems; $\mathrm{Zn}-\mathrm{Al}, \mathrm{Mg}-\mathrm{Al}$ and $\mathrm{Ca}-\mathrm{Al}$ were investigated. The syntheses were carried out with $\mathrm{M} 2+$ to $\mathrm{Al} 3+$ initial molar ratio, $\mathrm{R}$ of 4 . The $\mathrm{pH}$ of the mother liquor was maintained at $\mathrm{pH} 7.5$ and 10 during the synthesis, and the resulting mixture was aged at around $70{ }^{\circ} \mathrm{C}$ for about $18 \mathrm{~h}$. The intercalation of metanilate anion into the host was found to be strongly influenced by the M2+ that formed the inorganic metal hydroxide layers. Under our experimental condition, the formation of the nanohybrid materials was found to be more feasible for the $\mathrm{Zn}-\mathrm{Al}$ than for the other two systems, in which the former showed well-ordered layered organic-inorganic nanohybrid structure with good crystallinity. Intercalation is confirmed by the expansion of the interlayer spacing to about 15-17 $\AA$ when metanilate was introduced into the interlamellae of Zn-Al LDHs. In addition, CHNS and FTIR analyses also support that metanilate anion has been successfully intercalated into the interlamellae of the inorganic LDH. Apart from M2+, this study also shows that the initial $\mathrm{pH}$ of the mother liquor plays an important role in determining the physicochemical properties of the resulting nanohybrids, especially the mole fraction of the $\mathrm{Zn} 2+$ substituted by the $\mathrm{Al} 3+$ ion in the $\mathrm{LDH}$ inorganic sheets which in turn controlled the loading percentage of the organic anion, surface properties and the true density. Preliminary study shows that LDH can be used to host beneficial guests, active agent with controlled release capability of the guests. Generally the overall process is governed by pseudo second order kinetic but for the first $180 \mathrm{~min}$, the release process can be slightly better described by parabolic diffusion than the other models.
\end{abstract}

Keyword: Metanilate, Layered Double Hydroxide, Nanohybrid, Coprecipitation, Controlled Release 